\title{
ANALISIS KEBUTUHAN AIR IRIGASI PADA PERTUMBUHAN TANAMAN KAPAS (Gossypium hirtusum L.) DI KECAMATAN LAMURU, KABUPATEN BONE
}

\author{
Junaedi $^{1)}$, Syahruni Thamrin ${ }^{2)}$, Baso Darwisah ${ }^{3)}$, Budiman ${ }^{4)}$ \\ 1), 2), 3) Program Studi Budidaya Tanaman Perkebunan, 4) Program Studi Agribisnis Perikanan, \\ Politeknik Pertanian Negeri Pangkajene Kepulauan \\ Jalan Poros Makassar-Pare km 83, Mandalle Kabupaten Pangkep, Sulawesi Selatan \\ Email : junaedi_ppnp@yahoo.com
}

\begin{abstract}
ABSTRAK
Pengembangan tanaman kapas di Sulawesi Selatan masih terkendala oleh ketersediaan air yang dipengaruhi oleh curah hujan dan kemampuan tanah untuk menahan air, sehingga untuk mengoptimalkan pertumbuhan tanaman kapas perlu dilakukan metode khusus pemberian air.Penelitian ini bertujuan untuk menganalisis kebutuhan air irigasi dan memaksimalkan hasil produksi tanaman kapas dengan menggunakan aplikasi Cropwat 8.0 sebagai alternatif perhitungan kebutuhan air. Analisis perhitungan kebutuhan air irigasi tanaman kapas dengan Cropwat 8.0 dimaksudkan sebagai dasar untuk menentukan jumlah air yang akan diterapkan pada kegiatan irigasi dan menyediakan air irigasi.Hasil analisis kebutuhan air tanaman kapas yang dihitung berdasarkan fase pertumbuhan tanaman kapas menunjukkan nilai evapotranspirasi tanaman potensial (ETo) yang dihitung dengan program cropwat 8.0 mulai dari 3,12 - 4,53 mm/hari dan evapotranspirasi tanaman aktual (nilai ETc) mulai dari 1,06 - 4,56 $\mathrm{mm} /$ hari. Curah hujan efektif berkisar antara 5,9 - 15,7 $\mathrm{mm} /$ bulan. Jumlah total air yang diterapkan pada tanaman kapas adalah $512,5 \mathrm{~mm}$, kebutuhan air irigasinya adalah $213,3 \mathrm{~mm}$ dan jumlah maksimum yang dibutuhkan per bulan adalah $19 \mathrm{~mm}$.
\end{abstract}

Kata kunci: Cropwat, Kebutuhan Air Tanaman, Kapas

\begin{abstract}
The development of cotton crop in South Sulawesi is still constrained by the availability of water which is affected by rainfall and the ability of the soil to retain water, so to optimize the growth of cotton crop needs to be done special methods of giving water. This study aims to analyze the irrigation water needs and maximize the yield of cotton crop production by using Cropwat 8.0 application as an alternative calculation of water demand. Analysis of the calculation of irrigation water needs of cotton crop with Cropwat 8.0 is intended as a basis for determining the amount of water that will be applied to irrigation activities and providing irrigation water.The results of the analysis of the water needs of cotton crop are calculated based on the growth phase of cotton crop showed a reference evapotranspiration value (ETo) calculated with a cropwat 8.0 program ranging from $3.12-4.53 \mathrm{~mm} /$ day and plant evapotranspiration (ETc) values ranging from $1.06-4.56 \mathrm{~mm} /$ day. Effective rainfall ranges from $5.9-15.7 \mathrm{~mm} / \mathrm{month}$. The total amount of water was applied for cotton crop is $512.5 \mathrm{~mm}$. The irrigation water requirement was $213.3 \mathrm{~mm}$. The maximum amount needed per month is $19 \mathrm{~mm}$.
\end{abstract}

Keywords: Cropwat, Crop Water Requirements, Cotton 


\section{PENDAHULUAN}

Kapas (Gossypium hirsutum L.) adalah tanaman penghasil serat dan saat ini merupakan bahan baku utama untuk Industri Tekstil dan Produk Tekstil (ITPT) dari serat alami. Hingga saat ini, peran serat kapas masih lebih besar dari pada serat sintetis, terutama di negara tropis, termasuk Indonesia. Di sisi lain, produksi kapas dalam negeri hanya mampu memenuhi kebutuhan kapas nasional 0,1-2,3\% sehingga ketergantungan pada kapas impor sangat tinggi, yaitu lebih dari 97\% (Venti et al, 2018).

Pengembangan tanaman kapas di Sulawesi Selatan termasuk di Kabupaten Bone masih terkendala oleh ketersediaan air yang dipengaruhi oleh curah hujan dan kemampuan tanah menahan air, sehingga untuk mengoptimalkan pertumbuhan tanaman kapas perlu dilakukan metode khusus yakni penyediaan air melalui teknologi irigasi (Syahruni et al, 2018). Irigasi adalah alat penting untuk mengurangi periode ketersediaan air yang terbatas (Jordan et al., 2014).

Penelitian ini bertujuan untuk menganalisis kebutuhan air irigasi dan memaksimalkan produksi tanaman kapas dengan menggunakan aplikasi Cropwat 8.0 sebagai salah satu alternatif dalam perhitungan kebutuhan air. Perhitungan kebutuhan air dan irigasi dilakukan melalui penginputan data iklim, tanaman dan tanah, serta data irigasi dan hujan. Input data iklim yang dibutuhkan adalah evapotranspirasi potensial (bulanan) dan curah hujan (tahunan/bulanan/harian). Evapotranspirasi potensial dapat dihitung menggunakan suhu aktual, kelembaban, sinar matahari/radiasi dan data kecepatan angin berdasarkan metode Penman-Monteith (FAO, 1998). Program Cropwat 8.0 digunakan untuk menghitung evapotranspirasi tanaman (ETc), evapotranspirasi potensial (ETo), kebutuhan air irigasi dari satu jenis tanaman atau beberapa jenis tanaman. Cropwat 8.0 dirancang untuk menghitung evapotranspirasi dan studi kebutuhan air tanaman dan lebih khusus lagi untuk perencanaan dan pengelolaan jadwal irigasi (Marica, 2004).

Analisis perhitungan kebutuhan air irigasi tanaman kapas dengan Cropwat 8.0 dimaksudkan sebagai dasar dalam menentukan jumlah air yang akan diberikan melalui kegiatan irigasi dan penyediaan air irigasi. Perhitungan kebutuhan air irigasi tanaman pada lahan tadah hujan diharapkan dapat membantu dalam pemanfaatan sumber daya air yang terbatas sehingga tidak terjadi kekurangan air di musim kemarau. 


\section{BAHAN DAN METODE}

Penelitian ini dilaksanakan di Kabupaten Bone, dengan mengambil lokasi penelitian di lahan pertanian yang ada di Kecamatan Lamuru, tepatnya di Desa Turucinnae, yang berada pada 405' LS hingga 11909', BT dengan ketinggian tempat 126 meter dpl.

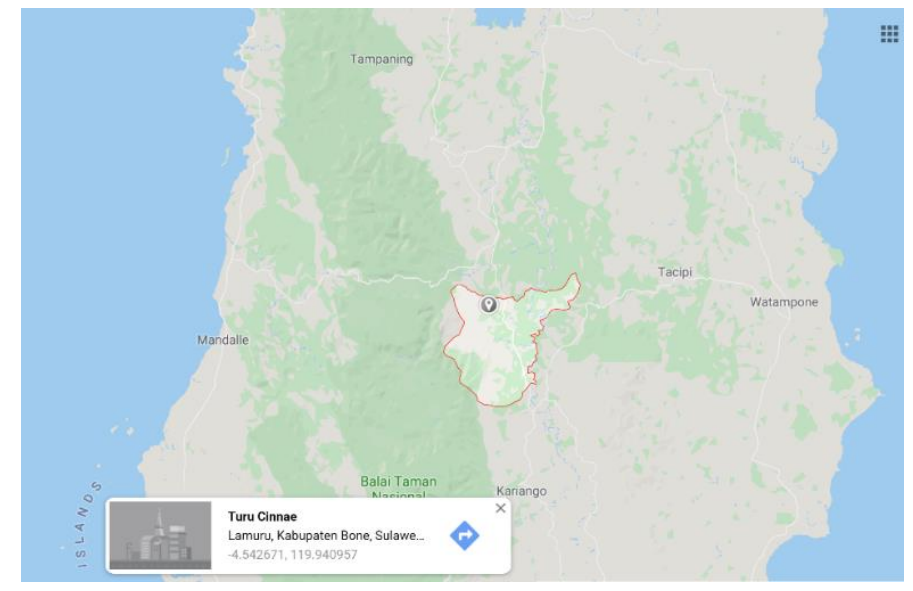

Gambar 1. Lokasi Penelitian

Penelitian dilakukan dengan mengumpulkan data primer dan data sekunder. Data primer yang diperoleh berkaitan dengan data tanah yang berasal dari lokasi penelitian, yang komponen datanya diperoleh berdasarkan hasil pengujian laboratorium di Laboratorium Tanah Maros. Sedangkan data sekunder diperoleh dari Stasiun Seli, Kabupaten Bone dalam bentuk data iklim selama 7 tahun terakhir sesuai ketersediaan data di lokasi penelitian yakni dari tahun $2012-2018$.

Teknik pengolahan data dalam penelitian ini menggunakan empat panel utama dalam program Cropwat 8.0, yaitu Climate/ETo, Rain, Crop dan Soil. Pengoperasiannya dilakukan dengan memasukkan data ke panel yang tersedia. Setelah semua data yang ada dimasukkan, hasil analisis kebutuhan air tanaman diperoleh pada panel CWR dan jadwal untuk menentukan nilai keseimbangan kelembaban tanah dan hasil produksi relatif tanaman kapas. Menurut Smith (1991), Cropwat merupakan kumpulan modul berdasarkan metode Penman-Monteith yang mengintegrasikan beberapa model yang diperlukan untuk memprediksi CWR, pengelolaan air irigasi dan penjadwalan tanaman. Program menghitung kebutuhan air tanaman berdasarkan periode (10 hari). CWR tergantung pada kondisi iklim, luas dan jenis tanaman, tipe tanah, musim tanam dan frekuensi produksi tanaman (FAO, 2009).

Metode Penman-Monteith yang disetujui FAO digunakan untuk memprediksi evapotranspirasi tanaman potensial (ETo), evapotranspirasi tanaman aktual (ETc) dan pengelolaan air irigasi (FAO, 1998; Smith, 1992). Perlu dicatat bahwa ETc menunjukkan 
jumlah air yang hilang akibat evapotranspirasi, sementara CWR adalah jumlah air yang akan dibutuhkan (Smith et al., 2009). CWR diperkirakan untuk setiap tanaman dan kemudian ditambahkan melalui perencanaan skema irigasi untuk memprediksi total kebutuhan air.

Seperti dijelaskan di atas, metode FAO Penman-Monteith sekarang menjadi satusatunya metode yang direkomendasikan untuk menentukan evapotranspirasi tanaman potensial (ETo). Metode ini mengatasi nilai-nilai yang lebih konsisten dengan data penggunaan air tanaman aktual di semua wilayah dan iklim. Perhitungan metode Penman-Monteith ditunjukkan melalui persamaan-persaman berikut (FAO, 1998);

$$
\mathrm{ET}_{\mathrm{o}}=\frac{0,408 \Delta\left(\mathrm{R}_{\mathrm{n}}-\mathrm{G}\right)+\gamma\left(\frac{900}{\mathrm{~T}+273}\right) \mathrm{u}_{2}\left(\mathrm{e}_{\mathrm{s}}-\mathrm{e}_{\mathrm{a}}\right)}{\Delta+\gamma\left(1+0,34 \mathrm{u}_{2}\right)}
$$

Keterangan;

$\mathrm{ET}_{\mathrm{o}}=$ Evapotranspirasi tanaman potensial $(\mathrm{mm} / \mathrm{hari})$

$\mathrm{R}_{\mathrm{n}}=$ radiasi bersih pada permukaan tanaman $\left(\mathrm{MJ} / \mathrm{m}^{2} /\right.$ hari

$\mathrm{G}=$ kepadatan fluks panas tanah $\left(\mathrm{MJ} / \mathrm{m}^{2} /\right.$ hari $)$

$\mathrm{T}=$ suhu udara rata-rata harian pada ketinggian $2 \mathrm{~m}\left({ }^{\circ} \mathrm{C}\right)$

$\mathrm{u}_{2}=$ Kecepatan angin pada ketinggian $2 \mathrm{~m}(\mathrm{~m} /$ detik)

$\mathrm{e}_{\mathrm{s}}=$ Tekanan uap saturasi $(\mathrm{kPa})$

$\mathrm{e}_{\mathrm{a}}=$ Tekanan uap aktual $(\mathrm{kPa})$

$\mathrm{e}_{\mathrm{s}}-\mathrm{e}_{\mathrm{a}}=$ Defisit tekanan uap jenuh $(\mathrm{kPa})$

Evapotranspirasi tanaman actual $\left(\mathrm{ET}_{\mathrm{c}}\right)$ dihitung untuk setiap tanaman melalui metode neraca air, seperti dalam persamaan berikut;

$$
\mathrm{ET}_{\mathrm{c}}=\mathrm{I}+\mathrm{P}-\mathrm{D}-\mathrm{R} \pm \mathrm{DS}
$$

Keterangan;

$\mathrm{I}=$ kedalaman irigasi (irrigation depth) $(\mathrm{mm})$

$\mathrm{P}=$ curah hujan (rainfall) $(\mathrm{mm})$

$\mathrm{D}=$ drainase $($ drainage $)(\mathrm{mm})$

$\mathrm{R}=$ limpasan permukaan (run off) ( $\mathrm{mm}$ )

$\mathrm{DS}=$ perubahan kelembaban tanah (the change in soil moisture) $(\mathrm{mm})$

Nilai harian koefisien tanaman dihitung untuk setiap tanaman menggunakan persamaan berikut;

$$
\mathrm{K}_{\mathrm{c}}=\mathrm{ET}_{\mathrm{c}} / \mathrm{ET}_{\mathrm{o}}
$$

Keterangan;

$\mathrm{K}_{\mathrm{c}}=$ koefisien tanaman pada tahap perkembangan tertentu

$\mathrm{ET}_{\mathrm{o}}=$ evapotranspirasi tanaman potensial $(\mathrm{mm} / \mathrm{hari})$

$\mathrm{ET}_{\mathrm{c}}=$ evapotranspirasi tanaman actual $(\mathrm{mm} / \mathrm{hari})$ 
Nilai Kc tergantung pada jenis tanaman, parameter tanah dan iklim (permukaan tanah, penguapan dan kecepatan dan arah angin) (FAO, 1998; Smith dan Kivumbi, 2006). Metode Penman-Monteith telah direkomendasikan FAO sebagai kombinasi yang sesuai dari parameter iklim yang relevan untuk memprediksi $\mathrm{ET}_{\mathrm{o}}$ (Mhashu, 2007).

\section{HASIL DAN PEMBAHASAN}

\section{Evapotranspirasi Potensial}

Program Cropwat 8.0 metode Penman-Monteith menggunakan data iklim bulanan (suhu, kelembaban relatif, kecepatan angin, lama penyinaran, dan curah hujan) untuk perhitungan evapotranspirasi tanaman potensial.



Gambar 2. Variasi Evapotranspirasi Bulanan di Kecamatan Lamuru Tahun 2012 - 2018

Hasil analisa sesuai grafik yang ditunjukkan pada Gambar 2 menggambarkan variasi evapotranspirasi bulanan, dimana evapotranspirasi maksimum terjadi pada bulan September dan evapotrasnpirasi minimum terjadi di bulan Mei. Besaran nilai evapotranspirasi tanaman setiap bulannya diuraikan pada tabel berikut. 
Tabel 1. Hasil Input Data Iklim Menggunakan Cropwat 8.0 di Kecamatan Lamuru Tahun 2012-2018

\begin{tabular}{|c|c|c|c|c|c|c|c|}
\hline \multicolumn{3}{|c|}{ Country lamuru } & \multirow[b]{2}{*}{ titude } & \multicolumn{4}{|c|}{ Station seli } \\
\hline Altitude & $26 \mathrm{~m}$. & & & " & \multicolumn{2}{|c|}{ Longitude $\longdiv { 1 1 9 . 0 0 }$} & $0 \quad W=$ \\
\hline \multirow[t]{2}{*}{ Month } & Min Temp & Max Temp & Humidity & Wind & Sun & Rad & ETo \\
\hline & ${ }^{\circ} \mathrm{C}$ & ${ }^{\circ} \mathrm{C}$ & $\%$ & $\mathrm{~km} / \mathrm{day}$ & hours & $\mathrm{MJ} / \mathrm{m}^{2} /$ day & $\mathrm{mm} / \mathrm{day}$ \\
\hline January & 20.0 & 30.0 & 65 & 21 & 8.0 & 21.8 & 4.15 \\
\hline February & 18.0 & 26.0 & 65 & 24 & 8.0 & 22.2 & 3.92 \\
\hline March & 22.0 & 29.0 & 63 & 23 & 8.0 & 22.1 & 4.15 \\
\hline April & 21.0 & 27.0 & 50 & 21 & 8.0 & 21.1 & 3.78 \\
\hline May & 18.0 & 26.0 & 45 & 19 & 8.0 & 19.6 & 3.12 \\
\hline June & 24.0 & 31.0 & 50 & 21 & 10.0 & 21.5 & 3.80 \\
\hline July & 18.0 & 26.0 & 55 & 19 & 8.0 & 19.1 & 3.15 \\
\hline August & 22.0 & 32.0 & 57 & 23 & 7.0 & 18.9 & 3.55 \\
\hline September & 24.0 & 32.0 & 60 & 21 & 9.0 & 23.1 & 4.53 \\
\hline October & 22.0 & 31.0 & 64 & 19 & 8.0 & 22.0 & 4.31 \\
\hline November & 22.0 & 30.0 & 68 & 19 & 8.0 & 21.8 & 4.24 \\
\hline December & 20.0 & 28.0 & 68 & 20 & 7.0 & 20.0 & 3.75 \\
\hline Average & 20.9 & 29.0 & 59 & 21 & 8.1 & 21.1 & 3.87 \\
\hline
\end{tabular}

Berdasarkan hasil analisis cropwat 8.0 ditemukan bahwa rata-rata nilai evapotranspirasi adalah $3,87 \mathrm{~mm} /$ hari dengan jumlah total nilai evapotranspirasi $46,45 \mathrm{~mm} /$ hari di mana nilai evaporatranspirasi maksimum bulan September adalah 4,53 $\mathrm{mm} / \mathrm{hari}$ sementara nilai evaporatranspirasi minimum di bulan Mei adalah 3,12 $\mathrm{mm} /$ hari.

\section{Curah Hujan Efektif}

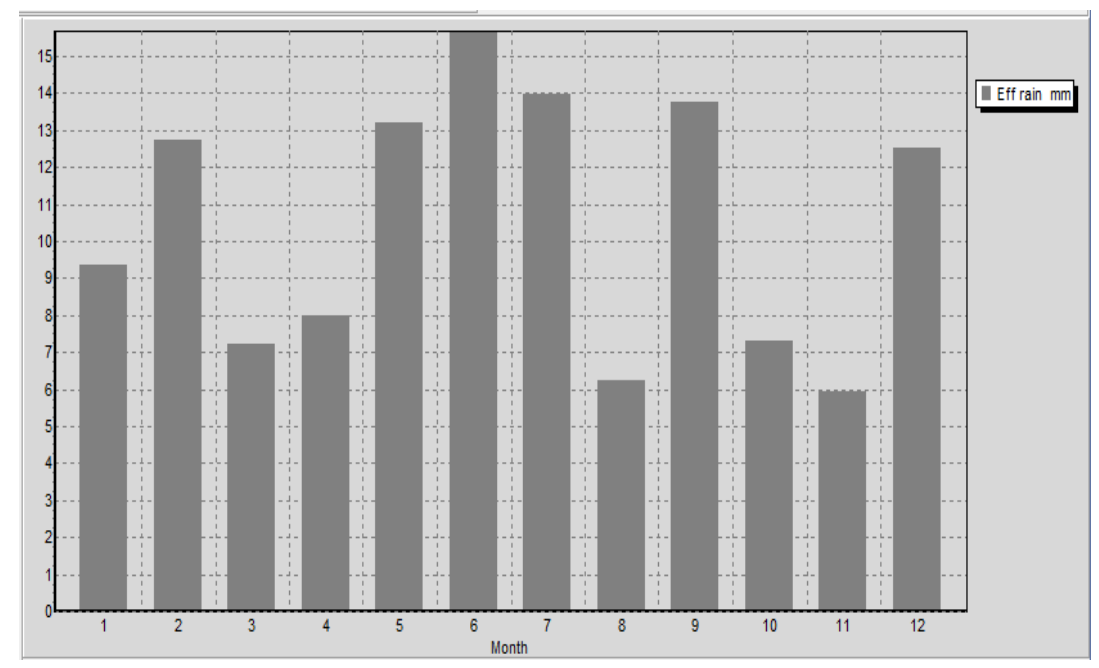

Gambar 3. Curah Hujan Efektif Bulanan di Kecamatan Lamuru Tahun 2012-2018

Berdasarkan grafik di atas, curah hujan efektif maksimum terjadi pada bulan Juni, di mana jumlah pasokan air lebih besar jika dibandingkan pada bulan November yang memiliki curah hujan efektif minimum. Total curah hujan selama 7 tahun terakhir adalah $1678.19 \mathrm{~mm}$. 


\section{Analisa Data Tanaman}



Gambar 4. Parameter Perkembangan Tanaman Kapas

Berdasarkan hasil Analisa pada gambar 4, tanaman kapas yang ditanam pada tanggal 7 Mei dan akan dipanen pada tanggal 2 November. Tanaman kapas memiliki usia total 180 hari yang terbagi pada beberapa fase pertumbuhan Periode perkecambahan awal 30 hari, periode perkembangan 50 hari, periode pertengahan 55 hari, dan 45 hari masa akhir pertumbuhan. Untuk nilai koefisien tanaman (Kc) yaitu sebesar 0,35 (periode awal), 1,20 untuk periode pertengahan dan 0,60 pada akhir musim (waktu panen).

\section{Analisa Data Tanah}

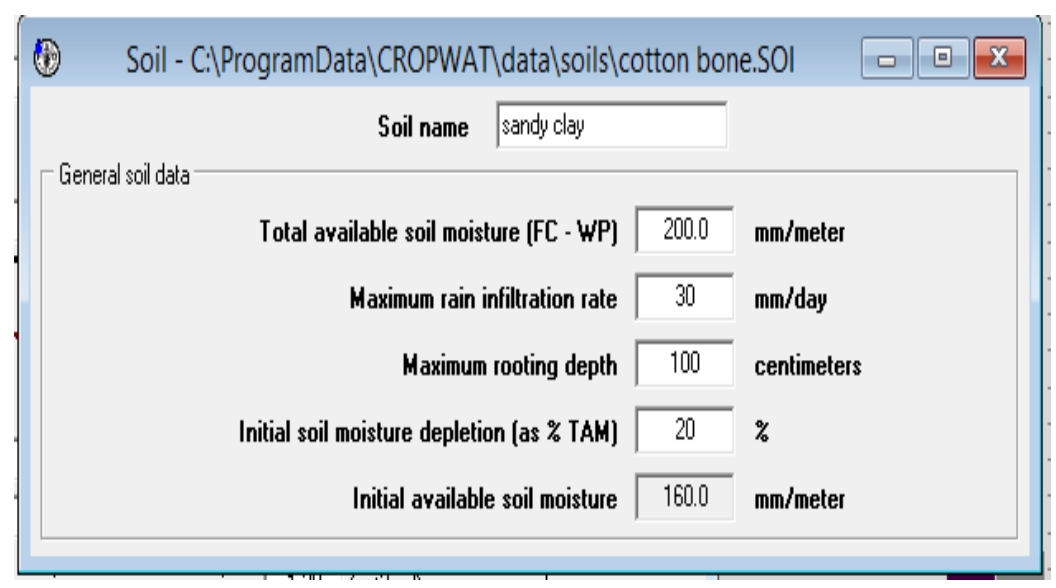

Gambar 5. Data Tanah pada Lokasi Penelitian di Kecamatan Lamuru 
Gambar di atas menunjukkan nilai laju infiltrasi ini cukup tinggi yaitu $30 \mathrm{~mm} /$ hari sehingga air akan dengan cepat memasuki tanah bagian dalam melalui mekanisme perkolasi. Sedangkan kedalaman maksimum akar tanaman kapas adalah $100 \mathrm{~cm}$ dengan jenis tanah liat berpasir.

\section{Kebutuhan Irigasi}

Variasi evapotranspirasi tanaman dan kebutuhan irigasi per periode untuk tanaman kapas berdasarkan hasil perhitungan Cropwat 8.0 dapat dilihat pada tabel berikut.

Tabel 2. Variasi Evapotranspirasi Tanaman dan Kebutuhan Irigasi Tanaman Kapas di Kecamatan Lamuru

\begin{tabular}{|c|c|c|c|c|c|c|c|}
\hline \multicolumn{8}{|c|}{ Crop Water Requirements } \\
\hline \multirow{2}{*}{\multicolumn{3}{|c|}{$\begin{array}{c}\text { ETo station seli } \\
\text { Rain station Seli }\end{array}$}} & & & \multicolumn{3}{|c|}{ Crop cotton } \\
\hline & & & & & \multicolumn{2}{|c|}{ Planting date } & $7 / 05$ \\
\hline Month & Decade & Stage & Kc & ETc & ETc & Eff rain & Irr. Req. \\
\hline & & & coeff & $\mathrm{mm} / \mathrm{day}$ & $\mathrm{mm} / \mathrm{dec}$ & $\mathrm{mm} / \mathrm{dec}$ & $\mathrm{mm} / \mathrm{dec}$ \\
\hline May & 1 & Init & 0.35 & 1.15 & 4.6 & 1.6 & 2.6 \\
\hline May & 2 & Init & 0.35 & 1.06 & 10.6 & 4.5 & 6.1 \\
\hline May & 3 & Init & 0.35 & 1.15 & 12.6 & 4.7 & 7.9 \\
\hline Jun & 1 & Init & 0.35 & 1.27 & 12.7 & 5.1 & 7.7 \\
\hline Jun & 2 & Init & 0.35 & 1.37 & 13.7 & 5.4 & 8.3 \\
\hline Jun & 3 & Deve & 0.43 & 1.56 & 15.6 & 5.1 & 10.5 \\
\hline Jul & 1 & Deve & 0.60 & 1.98 & 19.8 & 5.0 & 14.8 \\
\hline Jul & 2 & Deve & 0.77 & 2.36 & 23.6 & 4.9 & 18.7 \\
\hline Jul & 3 & Deve & 0.96 & 3.07 & 33.8 & 4.0 & 29.9 \\
\hline Aug & 1 & Mid & 1.10 & 3.76 & 37.6 & 2.5 & 35.1 \\
\hline Aug & 2 & Mid & 1.11 & 3.94 & 39.4 & 1.4 & 38.1 \\
\hline Aug & 3 & Mid & 1.11 & 4.30 & 47.3 & 2.5 & 44.9 \\
\hline Sep & 1 & Late & 1.07 & 4.56 & 45.6 & 4.2 & 41.4 \\
\hline Sep & 2 & Late & 0.92 & 4.25 & 42.5 & 5.2 & 37.2 \\
\hline Sep & 3 & Late & 0.76 & 3.45 & 34.5 & 4.3 & 30.2 \\
\hline Oct & 1 & Late & 0.61 & 2.67 & 26.7 & 3.0 & 23.7 \\
\hline \multirow[t]{2}{*}{ Oct } & 2 & Late & 0.51 & 2.20 & 6.6 & 0.7 & 5.5 \\
\hline & & & & & 427.3 & 64.0 & 362.5 \\
\hline
\end{tabular}

Berdasarkan tabel diatas dapat diketahui bahwa nilai evapotranspirasi tanaman aktual $\left(\mathrm{ET}_{\mathrm{c}}\right)$ memiliki nilai yang lebih rendah pada tahap awal, kemudian meningkat pada tahap pertengahan dan kembali menurun pada tahap akhir. Evapotranspirasi tanaman, curah hujan efektif dan kebutuhan air tanaman bervariasi masing-masing dari 1,06 - 4,56 mm/hari, 0,7-5,4 $\mathrm{mm} /$ detik dan 2,6-44,9 $\mathrm{mm} /$ detik.

\section{Penjadwalan Irigasi}

Perkiraan penjadwalan irigasi aktual dilakukan untuk tanaman kapas dapat dilihat pada Gambar 6. Jumlah total air yang dibutuhkan untuk tanaman kapas adalah 512,5 mm. Kebutuhan air irigasi adalah 213,3 mm. Jumlah maksimum yang dibutuhkan per bulan adalah $19 \mathrm{~mm}$. 




Gambar 6. Kebutuhan Air Tanaman Kapas di Kecamatan Lamuru

\section{KESIMPULAN}

Hasil analisis kebutuhan air tanaman kapas di Kecamatan Lamuru yang dihitung berdasarkan fase pertumbuhan tanaman kapas menunjukkan beberapa nilai berikut;

- Evapotranspirasi tanaman potensial $\left(\mathrm{ET}_{\mathrm{o}}\right)$ yang dihitung menggunakan program cropwat 8.0 sebesar $3,12 \mathrm{~mm} /$ hari hingga $4,53 \mathrm{~mm} /$ hari dan evapotranspirasi tanaman aktual untuk tanaman kapas (nilai $\mathrm{ET}_{\mathrm{c}}$ ) mulai dari 1,06 - 4,56 mm/hari.

- Curah hujan efektif berkisar antara 5,9 - 15,7 mm/bulan. curah hujan efektif maksimum terjadi pada bulan Juni, di mana jumlah pasokan air lebih besar jika dibandingkan pada November yang memiliki curah hujan efektif minimum $(5,9$ $\mathrm{mm} /$ bulan).

- Jumlah total air yang diterapkan untuk tanaman kapas sebesar 512,5 mm, kebutuhan air irigasinya adalah $213,3 \mathrm{~mm}$. dengan jumlah maksimum kebutuhan per bulan sebesar $19 \mathrm{~mm}$.

\section{UCAPAN TERIMA KASIH}

Dismapaikan terima kasih dan penghargaan kepada Direktorat Jenderal Pendidikan Vokasi, Kementerian Pendidikan dan Kebudayaan (Kemendikbud) yang telah mendanai penelitian ini. 


\section{DAFTAR PUSTAKA}

FAO, 1998. Crop Evapotranspiration by R. Allen, LA. Pereira, D. Raes \& M. Smith. FAO Irrigation and Drainage Paper No. 56. FAO, Rome.

FAO, 2009. CROPWAT Software, Food and Agriculture Organization, Land and Water Division; Available.

Jordan, D.L., P.D. Johnson, G.L. Grabow, and T. Corbett. 2014. Corn, Cotton, and Peanut Response to Tillage and Subsurface Drip Irrigation in North Carolina. Agron. J. 106:962-967.

Marica, A. 2004. Short Description Of The CROPWAT Model. http://www.fao.org/. Diakses tanggal 24 Nopember 2019.

Mhashu, S.V., 2007. Yield Response to Water Function and Simulation of Deficit Irrigation Scheduling of Sugarcane at Estate in Zimbabwe using CROPWAT 8.0 and CLIMWAT 2.0, Master thesis, Universita degli Studi di Firenze Facolta di Agraria (University of Florence, Faculty of Agriculture).

Smith B.A., Hoogenboom G, Mc Clendon R.W., 2009. Artificial Neural Networks for Automated Year-Round Temperature Prediction. Computers and Electronics in Agriculture; 68(1):52-61.

Smith M. 1992. CROPWAT- A computer program for irrigation planning and management. FAO Irrigation and Drainage paper 46.

Syahruni, T., Junaedi, B. Darwisah, 2018. Production of Cotton Plants Using Drip Irrigation in Two Different Planting Years. Agric. 30(2): 117-124.

Venti, E.,S., Suhartono, I. Hermawan, E. Budiyanti, R. Sari, 2018. Pengembangan Industri Tekstil Nasional: Kebijakan Inovasi \& Pengelolaan Menuju Peningkatan Daya Saing. Yayasan Pustaka Obor Indonesia, Jakarta. 